\title{
ASSESSING STUDENTS' ENGAGEMENT LEVELS DURING LOCKDOWN: A SURVEY IN TOURISM DEGREES
}

\author{
L. Chagas' ${ }^{1}$, A. Pires ${ }^{1}$, S. Pais ${ }^{1}$ \\ ${ }^{1}$ CiTUR - Centre for Tourism Research, Development and Innovation, Polytechnic Institute \\ of Leiria, Leiria, Portugal
}

In early 2020, the crisis of a new virus and a pandemic context took the world by storm. All sectors of society were affected: health, economics,... and education was no exception, with all levels suspending face-to-face classes, which were replaced by online activities.

In view of this situation, several doubts and uncertainties emerged among educators, but one question stood out: how to proceed with teaching activities in the online format without compromising the commitment and engagement of the students?

Within this context, the teachers involved in this study sought to adapt the activities and teaching materials to the exclusive use of technology and promoted asynchronous tasks, which could be developed independently by the students.

In order to understand how the profound changes in Higher Education were experienced by students, a quantitative survey was conducted. The participants in the study are undergraduate students from a Portuguese Higher Education institution attending the curricular units of Statistical Analysis and English.

Keywords: Distance Learning in Times of Crisis; COVID-19; Digital Technologies; Higher Education

\section{INTRODUCTION}

In early 2020, the coronavirus crisis and the ensuing pandemic context caught everyone by surprise, with all sectors of society being affected, particularly Education [1]. With regular face-to-face classes suspended and replaced by online activities, students and educators had to abruptly adjust to a new learning and teaching paradigm [2]. The need to adapt almost overnight to online teaching methods that implied new resources and skills brought numerous doubts and uncertainties to educators [3]. Although supported by online tools and activities, the teaching method put into practice in most institutions was that of Emergency Remote Teaching (ERT), as it lacked the proper planning required from online courses and was meant to be temporary [4].

Studies carried out to analyse this transition point out several issues felt by teaching staff, such as poor online teaching infrastructure, lack of experience and appropriate digital skills, lack of mentoring and support [5]. Among students, issues related to technological readiness and literacy, facilities (Internet access and computer access), financial and emotional difficulties, as well as specific domestic contexts were signaled as posing more difficulties in their adaptation to online learning [6]. In the specific context of higher education institutions in Portugal, Correia and Silva [7] reported that most of the factors pointed out by students as constraints to on-line learning had to do with teachers' attitudes and skills (limited digital skills and consequently very little confidence in the use of digital tools, conservative mentality and teaching methodologies). Respondents referred to positive aspects such as flexibility, centralization of resources on one platform, proximity between teacher and student and interactive resources, among others.

In January 2021, following a new wave of coronavirus infections, Portuguese authorities declared the second national lockdown and the restrictive measures affected all levels of education once again, so a new stage of emergency remote teaching had to be put into practice. Although in this article we refer to the broad concept of online classes as the new method the authors had to resort to, the fact that this adaptation had to be carried out once again with no time for thorough planning, meant it was a second version of ERT. Therefore, and in spite of the use of new strategies and tools, the activities that were 
designed throughout the semester were not entirely self-paced and mostly asynchronous as online learning implies.

As had already been the case during the 2020 period of emergency remote teaching, the adaptation process followed by the authors of this study to this second lockdown challenge was guided by this one question: how to proceed with teaching activities in the online format without compromising the commitment and engagement of the students?

This article reports (1) some of the different strategies and methodologies used in different curricular units of undergraduate courses in the field of Tourism; and (2) students' opinions regarding the methodologies used and/or the results achieved.

\section{METHODOLOGY}

The purpose of this study is to understand how the profound changes in higher education, resulting from the COVID-19 pandemic in Portugal, were perceived by students, particularly in the area of English and Statistics. Taking that into consideration, the authors developed a questionnaire and the participants were students attending curricular units (CUs) of English and Applied Statistics of undergraduate degrees in the field of Tourism from a Portuguese higher education institution.

In view of the pandemic situation and the consequent suspension of face-to-face classes, the educators involved in this study attempted to adapt the activities and teaching resources for the exclusive use of technology and promoted asynchronous tasks that could be developed autonomously by the students.

The questionnaire aimed to assess students' views regarding the methodologies used by the educators involved in this study. After data collection, qualitative analyses were carried out, quantified whenever necessary and possible. Statistical analyses were performed with Excel and Statistical Package for the Social Sciences (SPSS), version 27.

\subsection{Description of the study}

Given the specificity of each of the CUs involved in this study, the approaches (strategies and methodologies) developed by the teachers were also different. Thus, in remote emergency teaching classes, the following approaches were used:

\subsubsection{Applied Statistics}

The classes had a total duration of 2 hours and 30 minutes. This time was divided into synchronous sessions taking place on the Zoom-Colibri platform (lasting from 1 hour to 1 hour and 30 minutes) and asynchronous sessions (for the remaining time).

At the beginning of each week, the teacher uploaded a study guide on Moodle, with the objective of allowing students to manage their time and to organize their work. In the synchronous sessions, the teacher used expository and demonstrative classes, resorting to commented materials (such as PPT presentations) and solving exercises on a white board. For self-assessment of the assimilation and understanding of the contents taught, formative tasks were introduced. These tasks were worked out asynchronously, individually or in groups, at the end of each synchronous session. During the asynchronous time of the class, the students used the doubts forum, created on Moodle, to clarify questions that arose in relation to the assigned task, and the teacher answered in real time. In the end, they uploaded the resolution of the task in a digital locker created on Moodle for the purpose. 
Subsequently, the teacher also placed the correction of the task on Moodle, and the students would proceed with the self-correction. If there were any doubts related to the task, they would send an email to the teacher in order to ask for support to clarify those doubts. At the beginning of the next synchronous session, the teacher started by asking if there was still any doubt to clarify.

\subsubsection{English}

Some classes had a total duration of three hours, divided in two classes of one hour and a half each, on different days. At the beginning of the week there would be a synchronous session on Zoom to correct and discuss exercises, introduce and discuss new topics and present the activities to be carried out asynchronously on the next session. All materials would be uploaded on Moodle, where a "doubts forum" was available weekly for the asynchronous activities.

There was also a different approach in English, namely one that involved asynchronous activities which were planned to prepare online sessions. These activities would include reading texts about a specific theme, listening activities or vocabulary exercises, for example. The synchronous activities were mainly designed to develop students' speaking skills but also collaboration, in order to develop a sense of community in the online learning environment. More specifically, some examples of activities included role-playing tasks, debates, research activities, discussing and creating solutions for real-life problems or collaborative writing tasks, among others.

\subsection{Respondents}

The respondents in this quantitative study were 141 undergraduate students who were learning either English or Statistics in a Tourism-related degree from a Portuguese higher education institution, in the second semester of 2020/2021.

The great majority of respondents (95\%) were full-time students, under 25 (95.7\%). Most respondents were English students (62.4\%), whereas $37.5 \%$ were studying Statistics. Finally, $76.3 \%$ out of 139 students stated they were female and $23.7 \%$ stated they were male. This was a convenience sample, as participants were easily accessible to researchers.

\section{RESULTS AND DISCUSSION}

In reference to the circumstances and measures associated with COVID-19, respondents assessed their degree of satisfaction with the transfer of classes to the online delivery system and instructions received on the use of tools.

Only about $26 \%$ of respondents say they are not satisfied with the transfer of classes to the online delivery system, while about $45 \%$ say they are satisfied and $28 \%$ say they were indifferent (figure 1 ). 


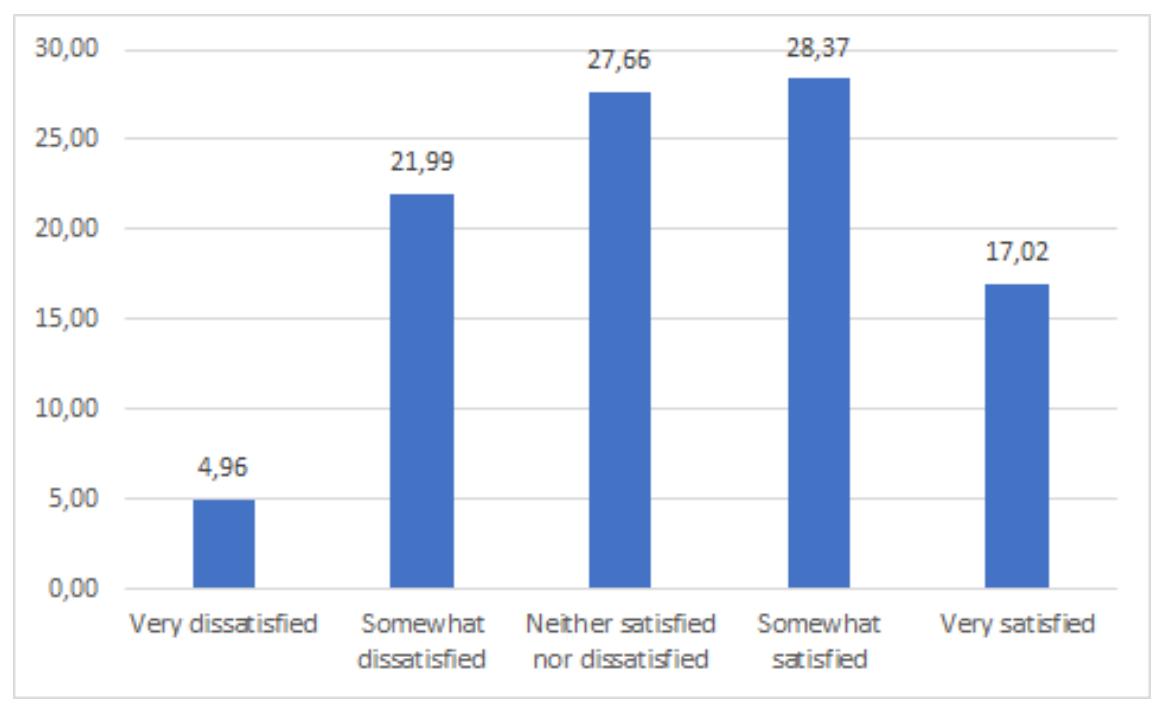

Figure 1. Student satisfaction regarding transfer to the online delivery system.

When asked about the instructions received on the use of tools such as Moodle and Zoom, the vast majority of respondents (about 62\%) say they are satisfied. The percentage of students who say they are not satisfied is less than $9 \%$. The survey results are presented in figure 2 .

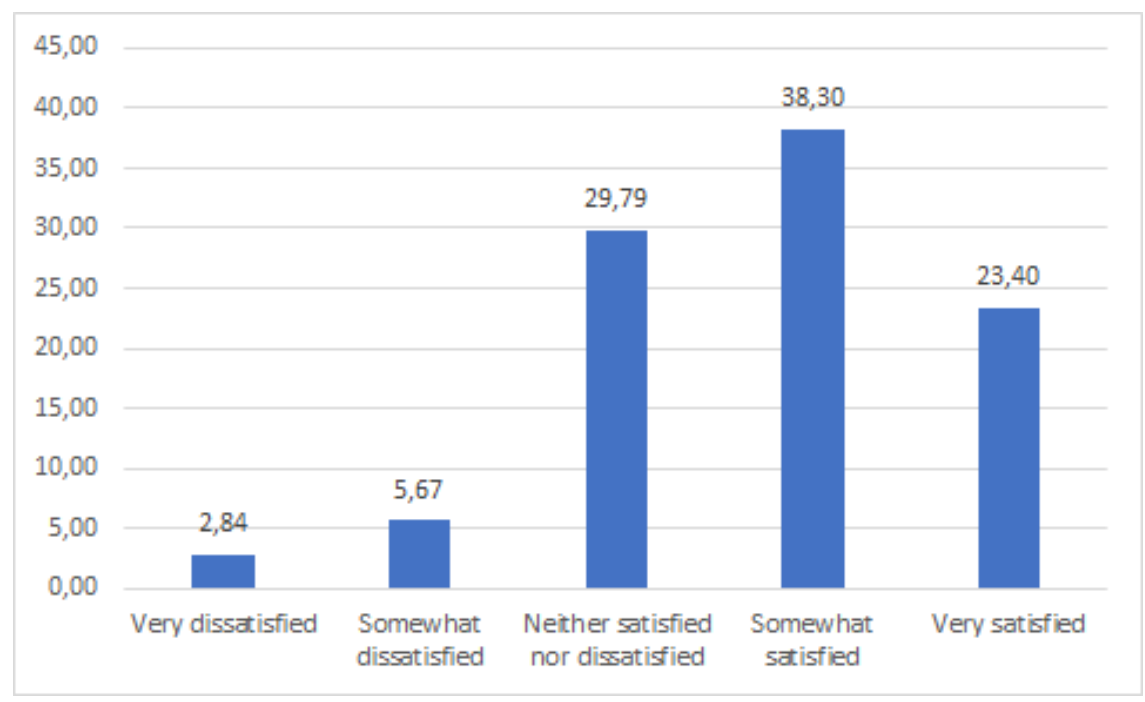

Figure 2. Student satisfaction regarding instructions for Moodle and Zoom.

Most of the students surveyed attributed a high degree of satisfaction to all online solutions adopted. Regarding the solutions "access to online resources" (75.36\%); "Asynchronous communication with teachers" (73.53\%); "Use of distance learning platforms" (71.74\%) and "commented materials" (70.29\%) more than $70 \%$ of the students surveyed considered to be satisfied (table 1 ). 
Table 1. Student satisfaction with online solutions.

\begin{tabular}{l|c|c|c|c|c}
\hline \hline & $\begin{array}{c}\text { Very } \\
\text { dissatisfied (\%) }\end{array}$ & $\begin{array}{c}\text { Somewhat } \\
\text { dissatisfied (\%) }\end{array}$ & $\begin{array}{c}\text { Neither } \\
\text { satisfied nor } \\
\text { dissatisfied (\%) }\end{array}$ & $\begin{array}{c}\text { Somewhat } \\
\text { satisfied (\%) }\end{array}$ & $\begin{array}{c}\text { Very } \\
\text { satisfied } \\
(\%)\end{array}$ \\
\hline Online classes & 4,96 & 19,86 & 15,60 & 39,01 & 20,57 \\
\hline Videos & 7,27 & 6,36 & 33,64 & 31,82 & 20,91 \\
\hline $\begin{array}{l}\text { Commented } \\
\text { materials }\end{array}$ & 4,35 & 2,90 & 22,46 & 42,75 & 27,54 \\
\hline $\begin{array}{l}\text { Use of distance } \\
\text { learning } \\
\text { platforms }\end{array}$ & 2,90 & 8,70 & 16,67 & 50,00 & 21,74 \\
\hline $\begin{array}{l}\text { Access to } \\
\text { online } \\
\text { resources }\end{array}$ & 1,45 & 5,80 & 17,39 & 52,90 & 22,46 \\
\hline Doubts forums & 3,70 & 0,74 & 35,56 & 42,22 & 17,78 \\
\hline $\begin{array}{l}\text { Asynchronous } \\
\text { communication } \\
\text { with the } \\
\text { teachers }\end{array}$ & 3,68 & 0,74 & 22,06 & 47,79 & 25,74 \\
\hline $\begin{array}{l}\text { Tasks carried } \\
\text { out } \\
\text { asynchronously }\end{array}$ & 4,26 & 9,22 & 24,11 & 39,01 & 23,40 \\
\hline \hline
\end{tabular}

Approximately $93 \%$ of respondents consider that they had all the resources and conditions necessary to continue studying remotely. It should be noted that even though almost all students (96.5\%) indicated that they had access to the internet, $3.5 \%$ mentioned they did not have access to the internet. Access to essential facilities (such as the internet) has been stressed as one of the main issues of learning during a pandemic, and its lack may be regarded as a factor promoting inequality among students [6]. Regarding whether or not they have a computer at their disposal, $91.5 \%$ of the students indicated that they had their own computer and $5.7 \%$ indicated that they had a shared computer. This leads us to conclude that $2.8 \%$ of students did not have access to a computer.

Of those students who did not have access to a computer (4 students out of a total of 141), only two had a smartphone, with the other two students referring to having neither access to a computer nor a smartphone. Only $75.9 \%$ of respondents indicated having access to a quiet and private space to attend classes and study during confinement, which means that about $24 \%$ of students did not. More than $90 \%$ of respondents indicated having access to a camera (90.8\%) and microphone (91.5\%). However, only $81.6 \%$ indicated having access to videoconferencing tools (figure 3 ). 


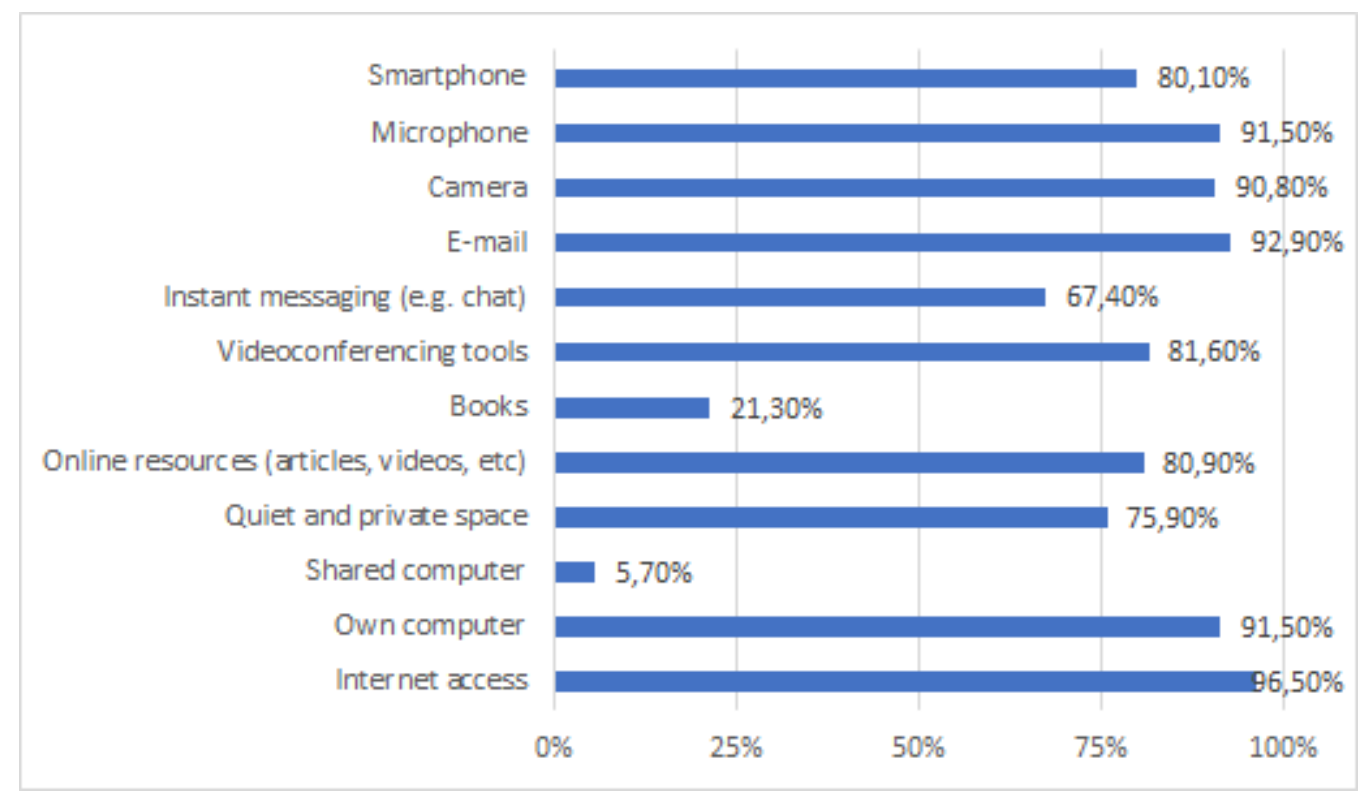

Figure 3. Resources that allowed students to continue studying remotely.

Only $42.6 \%$ of respondents said that the internet connection was of good quality, which means that more than $50 \%$ did not have a good quality connection. More than $70 \%$ of respondents said they had difficulty concentrating and only $14.2 \%$ said they felt more motivated. A study developed by AguilleraHermida [8] reported similar results regarding low levels of concentration and motivation. $41.8 \%$ of respondents consider that they have developed autonomy skills, and $36.9 \%$ considered that they did a good time management. $41.8 \%$ mentioned they had difficulty following the contents. Around $70 \%$ of the respondents consider that they can easily interact with the teacher and $51.8 \%$ considered the format of the classes to be adequate (figure 4).

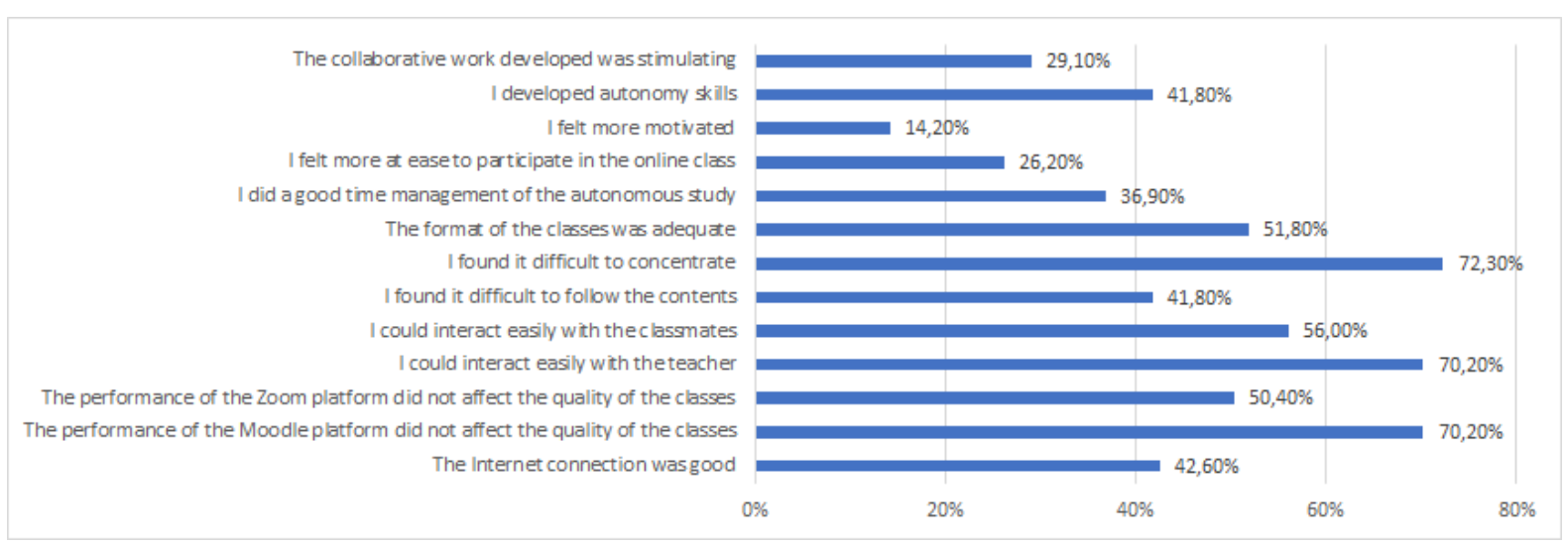

Figure 4. Students' views regarding the online classes attended.

In an open-ended question, students were asked to list the resources they couldn't take advantage of, but that would have allowed them to continue studying remotely. The answers that stand out refer to: a 
fast/stable internet connection (six references); a personal computer (four references); more recorded sessions (three references).

A study by Shim and Lee [3] showed similar results, with reference to specific areas that students believe should be improved, namely network stabilization and recorded lecture sharing. On the other hand, Gonzalez-Ramirez et al. [9] found out that two barriers students encountered in the context of emergency online learning were connected to Wi-Fi quality and finding a quiet space to study. Similarly, Katz, Jordan and Ognyanova [10] state that different access to high-speed internet and digital devices are associated with lower remote learning proficiency and can even lead to digital inequality. Analogously, a study by Shim and Lee [3] revealed that "network instability, unilateral interactions, and reduced concentration were shown to be causes of students' complaints" (p.1).

The vast majority of students $(58,87 \%)$ reveal that they are satisfied with the format of the online classes, with the percentage of students that reveal to be very dissatisfied being inferior to $5 \%$ in the four points under analysis. The point with the lowest percentage of satisfied students is "Asynchronous work" with $51.06 \%$ of respondents saying they are satisfied, $31.91 \%$ saying they are neither satisfied nor dissatisfied and $17.02 \%$ saying they are not satisfied. It should be noted that with regard to the "Proportion of time between synchronous sessions and asynchronous work", only $10 \%$ of respondents say they are somewhat dissatisfied and $1.43 \%$ say they are very dissatisfied (figure 5 ).

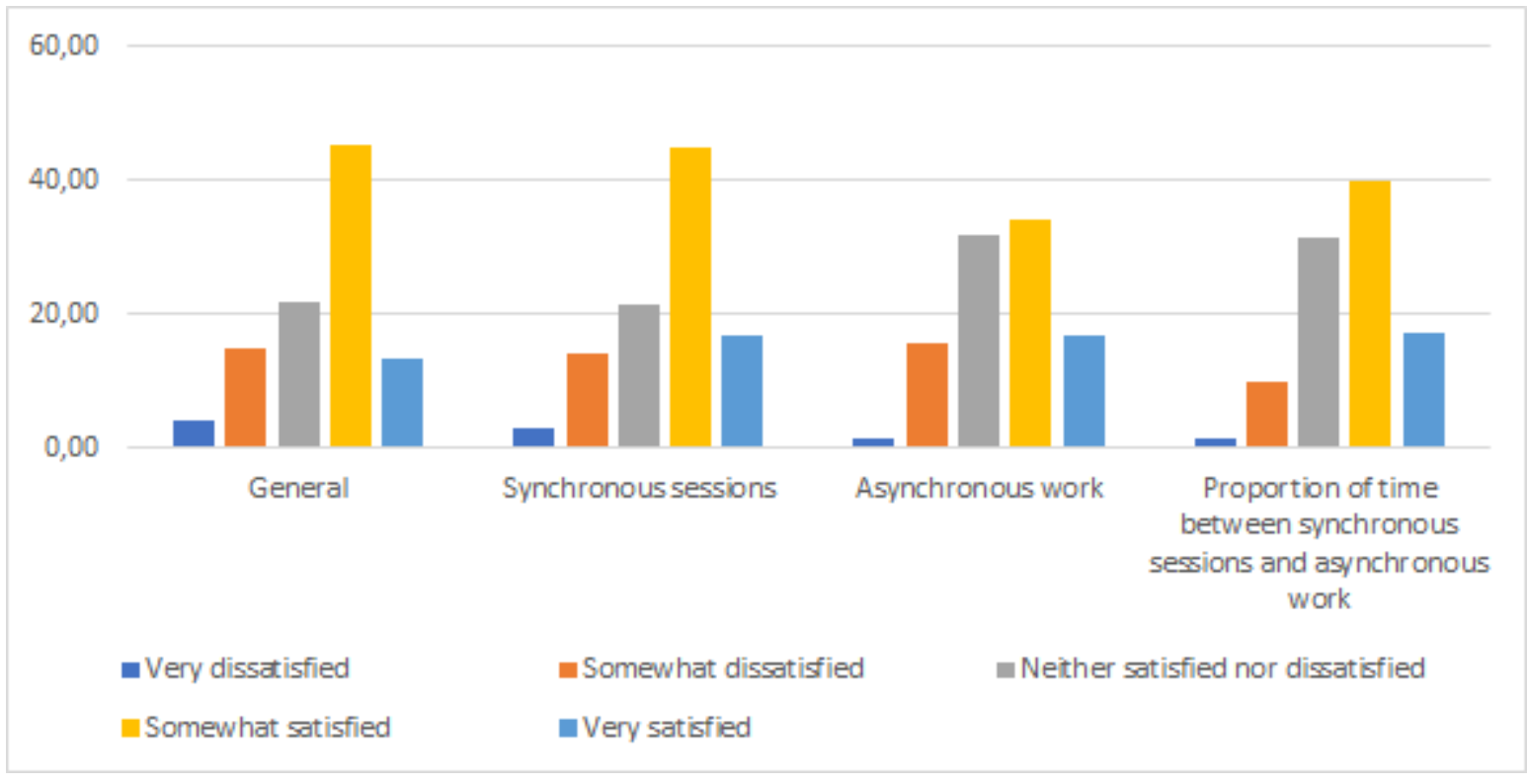

Figure 5. Student satisfaction regarding the format of online classes.

A Portuguese study from another Polytechnic institution [7] showed similar results, as most students declared themselves as being satisfied with the vidoconferencing platftorm (Zoom) and with the asynchronous activities developed with Moodle.

The vast majority of respondents have a positive opinion both regarding their performance as a student $(54,61 \%)$ and regarding the performance of the teacher $(74,29 \%)$ in this period. Only $2.13 \%$ of the students revealed to be very dissatisfied with their performance and $19.15 \%$ revealed to be somewhat dissatisfied. Regarding the overall performance of the teacher, no student reveals to be very dissatisfied and $4.29 \%$ reveals to be somewhat dissatisfied. When asked about the possible continuation of the 
ERT, the respondents' opinion is no longer so consensual: $48.23 \%$ of the respondents are receptive to this idea, while $35.46 \%$ indicate that they are not very receptive. About $16 \%$ of respondents are indifferent to this idea. It is also important to mention that there is a considerable percentage (between $15.60 \%$ and $35.56 \%$ ) of respondents who are indifferent to all this (answering "neither satisfied nor dissatisfied"). The results are shown in figure 6.

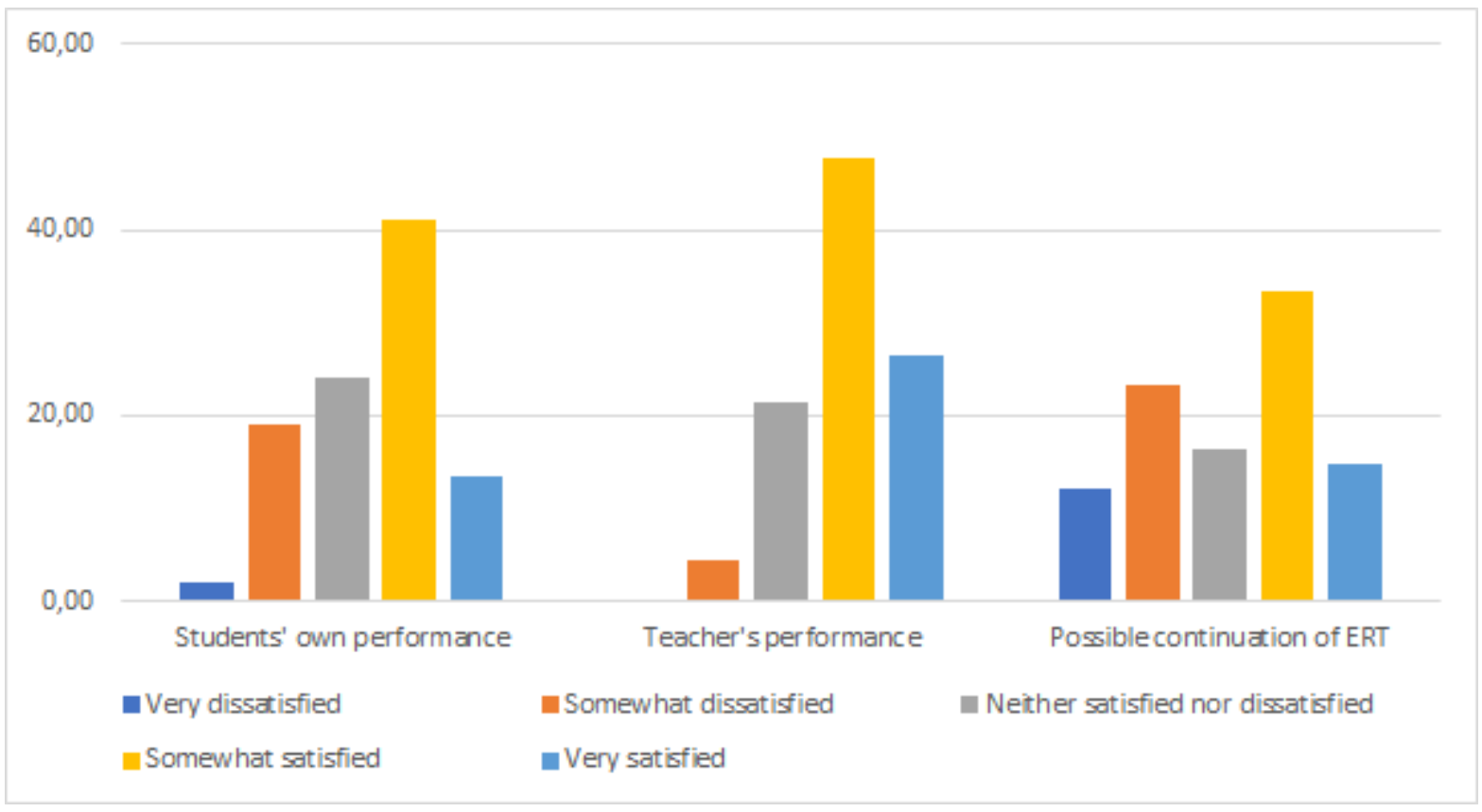

Figure 6: Student satisfaction regarding performance and continuation of ERT.

The fact that the majority of students were satisfied with their own performance is supported by recent studies highlighting the positive impact that self-efficacy has on learning outcomes and the use of educational technologies. Students who are confident in their skills to learn are also more motivated and become more engaged in the learning process [11].

\section{CONCLUSIONS}

This study explored the perception of Tourism students in the transition to emergency remote teaching, regarding not only the resources they had available to study, but also other factors such as interaction, concentration, time management, motivation, collaboration and autonomy. Results show that students' experience was somehow positive, although there are clear challenges that need to be overcome, specifically the access to a personal computer and to high-speed internet.

The most positive results are related to the satisfaction with synchronous sessions, students' own performance and the teacher's performance. The fact that there were high satisfaction scores despite the technical problems that affected some students is also worth noting. In this context, it is important to mention a study [12] in which the authors reported their experience with ERT and listed the main factors that influence the remote delivery system. They argue that strong relationships between students and their instructor can promote student motivation and engagement. 
Further research is required to assess how this emergency method influences students' academic performance, as a study [1] showed that "overall academic performance of students in emergency remote conditions was significantly better than traditional face-to-face instruction (p.8). Other factors that would be worth investigating are related to how ERT may influence the institution's adoption of online learning in the future or the development of autonomy skills, as there aren't many studies regarding this theme. With respect to the limitations of the study, it is important to mention that our study used convenience sampling and that results cannot be generalised.

Overall, we believe that our study contributes to a better understanding of the students' response to online activities, while signalling issues that require attention from the higher education institutions, namely about facilities or equipment.

\section{ACKNOWLEDGEMENTS}

This work is financed by national funds through FCT - Foundation for Science and Technology, IP, within the scope of the reference project UIDB/04470/2020.

\section{REFERENCES}

[1] S.Iglesias-Pradas, Á. Hernández-García, J. Chaparro-Peláez, and J.L.Prieto, "Emergency remote teaching and students' academic performance in higher education during the COVID-19 pandemic: A case study," Computers in Human Behavior, vol. 119, pp.1-18, 2021.doi: https://doi.org/10.1016/j.chb.2021.106713

[2] UNESCO, "Education: From disruption to recovery," 2020. Retrieved from: https://en.unesco.org/covid19/educationresponse. Accessed 20 April 2021.

[3] T.E. Shim, and S.Y. Lee, "College students' experience of emergency remote teaching due to COVID-19," Children and youth services review, vol. 119, pp.1-7, 2020. doi:105578.

[4] C. Hodges, S. Moore, B. Lockee, T.Trust, and A. Bond, "The difference between emergency remote teaching and online learning," Educause review, 2020.Retrieved from: https://er.educause.edu/articles/2020/3/the-difference-between-emergency-remote-teaching-andonline-learning. Accessed 20 April 2021.

[5] C. Carrillo,and M.A. Flores, " COVID-19 and teacher education: a literature review of online teaching and learning practices," European Journal of Teacher Education, vol. 43,no.4, pp. 466-487, 2020.doi:10.1080/02619768.2020.1821184

[6] F. Ahmadon, H.I.M. Ghazalli, and H.M. Rusli, "Studying during Pandemic: A Review of Issues from Online Learning in the Middle of COVID-19," 2020 6th International Conference on Interactive Digital Media (ICIDM), pp.1-4, 2020. doi:10.1109/ICIDM51048.2020.9339644

[7] M. Correia, and P.S. Silva, "Higher Education Polytechnic Students' Perspectives on the Transition to Emergency Remote Teaching," SIIE 2020-22nd International Symposium on Computers in Education, vol. 2733, 2020.doi: 0074-2733-7. 
[8] A. P. Aguilera-Hermida, "College students' use and acceptance of emergency online learning due to Covid-19", International Journal of Educational Research Open, vol. 1, 2020. http://dx.doi.org/10.1016/j.jjedro.2020.100011

[9] J. Gonzalez-Ramirez, K. Mulqueen, R. Zealand, S. Silverstein, C. Mulqueen, and S. BuShell, "Emergency Online Learning: College Students' Perceptions During the COVID-19 Pandemic," College Student Journal, vol. 55, no.1, pp. 29-46, 2021. doi: https://dx.doi.org/10.2139/ssrn.3831526

[10] V. S. Katz, A. B. Jordan, and K. Ognyanova, "Digital inequality, faculty communication, and remote learning experiences during the COVID-19 pandemic: A survey of US undergraduates". Plos one, vol. 16, no. 2, e0246641, 2021. https://doi.org/10.1371/journal.pone.0246641

[11] A.P. Aguilera-Hermida, A. Quiroga-Garza, S. Gómez-Mendoza, C.A. Villanueva, B.A. Alecchi, and D. Avci, "Comparison of students' use and acceptance of emergency online learning due to COVID19 in the USA, Mexico, Peru, and Turkey", Education and Information Technologies,2021. https://doi.org/10.1007/s10639-021-10473-8

[12] S.L.Gares, J.K. Kariuki, and B.P. Rempel, "CommUnity matters: Student-instructor relationships foster student motivation and engagement in an emergency remote teaching environment", Journal of Chemical Education, vol. 97, no.9, pp.3332-3335, 2020.

https://doi.org/10.1021/acs.jchemed.0c00635 